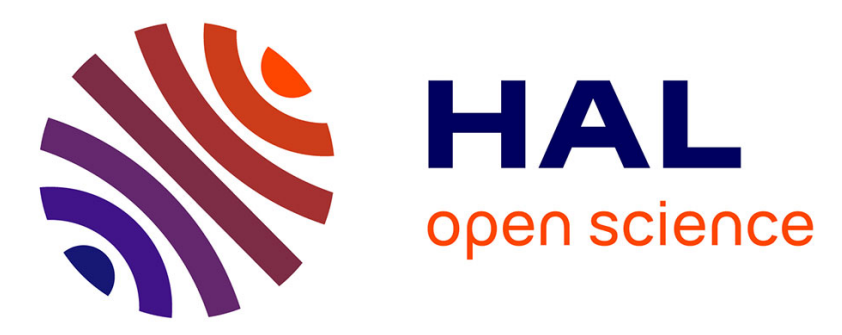

\title{
Which pitfall traps and sampling effort to choose to evaluate cropping system effects on spider and carabid assemblages?
}

Antoine Gardarin, Muriel Valantin-Morison

\section{- To cite this version:}

Antoine Gardarin, Muriel Valantin-Morison. Which pitfall traps and sampling effort to choose to evaluate cropping system effects on spider and carabid assemblages?. Environmental Entomology, 2021, 50, pp.256 - 266. 10.1093/ee/nvaa145 . hal-03328550

HAL Id: hal-03328550

https://hal-agroparistech.archives-ouvertes.fr/hal-03328550

Submitted on 30 Aug 2021

HAL is a multi-disciplinary open access archive for the deposit and dissemination of scientific research documents, whether they are published or not. The documents may come from teaching and research institutions in France or abroad, or from public or private research centers.
L'archive ouverte pluridisciplinaire HAL, est destinée au dépôt et à la diffusion de documents scientifiques de niveau recherche, publiés ou non, émanant des établissements d'enseignement et de recherche français ou étrangers, des laboratoires publics ou privés. 


\title{
Which pitfall traps and sampling effort to choose to evaluate cropping system effects on spider and carabid assemblages?
}

\author{
Antoine Gardarin* et Muriel Valantin-Morison
}

Environmental Entomology, 50 (1) : 256-266 ; doi: 10.1093/ee/nvaa145

UMR Agronomie, INRAE, AgroParisTech, Université Paris-Saclay, 78850 ThivervalGrignon, France

* Corresponding author: Antoine Gardarin, UMR Agronomie, INRAE, AgroParisTech, Université Paris-Saclay, 78850 Thiverval-Grignon, France. Tel : +33 130815440. Antoine.Gardarin@inrae.fr

\begin{abstract}
In arable agroecosystems, arthropod communities often have a reduced abundance and diversity, which represents a challenge for sampling techniques needed to detect small differences among these simplified communities. We evaluated the suitability of pitfall traps for comparing the effects of cropping systems on arthropod communities. In a field experiment, we compared the effects of two pitfall trap diameters, the type of preserving fluid and the sampling effort on three metrics (activity-density, taxonomic richness and community weighted mean [CWM] of body size) for carabids and spiders. Trap size affected the observed composition of communities, with large traps yielding a higher proportion of spiders, and a higher richness and CWM body size for both taxa. The type of preserving fluid had a weaker effect. Simulations with various sampling efforts showed that only very different communities could be distinguished with less than ten traps per field or less than 30 field replicates. Fewer traps were required to find differences between cropping systems for body size than for other metrics. Carabid activity-density and body size, and spider genus richness, were the variables better distinguishing between cropping systems with the smallest sampling effort. A high sampling effort was required for comparing activity-density and richness across cropping systems. Selection of the most appropriate trap design, metrics and crops are the main factors for optimizing the trade-off between sampling effort and the ability to detect arthropod community responses to habitat management.
\end{abstract}

\section{Keywords}

Activity-density; CWM body size; Preserving fluid; Taxonomic richness; Trap diameter 


\section{Introduction}

At a time when agriculture is facing many challenges (biodiversity loss, climate change and dependence on synthetic inputs), innovative sustainable cropping systems targeting multiple issues must be designed and assessed (Foley et al. 2011). Agricultural techniques that enhance the biodiversity of soil organisms, such as ground-dwelling arthropods, not only promote conservation biological control (Thérond et al. 2017), but also support higher trophic levels. Ground-dwelling arthropods have important roles in the dynamics of soil functioning and associated ecosystem services (González et al. 2020). In agroecosystems, carabids and spiders are important predators that regulate phytophagous insect and weed populations (Kromp 1999, Marc et al. 1999). The impact of these organisms depends on the density, the richness and functional composition of their communities (Rusch et al. 2015, Jonsson et al. 2017). Assessing arthropod communities under different cropping systems can help reveal whether a cropping system preserves soil biodiversity, its functioning and the associated services.

Pitfall traps are widely used to sample ground-dwelling arthropod assemblages (Woodcock 2005). The design of pitfall traps varies considerably between studies, and a number of features, including the trap diameter and the type of preserving fluid, have been shown to have a significant impact on capture rates (Knapp and Ruzicka 2012, Brown and Matthews 2016). Several methodological studies have been performed (Work et al. 2002, Lange et al. 2011, Corti et al. 2013) in natural or seminatural habitats, such as forests, grasslands and riverbeds, but less frequently in agroecosystems (Holland and Smith 1999, Lövei and Magura 2011). In natural ecosystems, the vegetation has a different architecture than in agroecosystems (litter often buried by tillage, bare soil between rows, and less diverse vegetation), which has known effects on beetle communities ( $\mathrm{Ng}$ et al. 2018). It remains thus unclear to what extent the results of methodological studies realized in natural ecosystems can be generalized to characterize the simplified communities of agroecosystems.

First, trap diameter varies considerably between studies (Brown and Matthews 2016). Largediameter pitfall traps collect more individuals of all taxa than smaller traps, but they also collect more individual spiders (Lycosidae), more spider species and fewer small carabid individuals than expected when the catch rates are corrected for trap circumference (Work et al. 2002, Lange et al. 2011). Indeed, capture rates depend on the mobility and behavior of the organisms. In arable fields, where the architecture of the surface vegetation is different than in natural habitats, ground-dwelling arthropods are likely to be more mobile, potentially reducing the effect of trap diameter on capture rates (Halsall and Wratten 1988).

Second, many types of preserving fluids are available, and the pros and cons of each have been hotly debated (Schmidt et al. 2006, Brown and Matthews 2016). Ethylene glycol and formalin are the most widely used (Work et al. 2002, Lange et al. 2011), as they are highly effective due to their capture efficiency and their ability to preserve dead individuals (Jud and SchmidtEntling 2008). However, both are toxic. Propylene glycol, which has been developed more recently, is both nontoxic and very efficient for collecting carabids individuals and is suitable for estimating their community richness (Knapp and Ruzicka 2012, Knapp et al. 2016). Salt water and vinegar are other possible cheap alternatives, and water offers the further advantage allowing use of the material for DNA analyses if the samples are collected before they start to decay and stored in ethanol afterwards. Water and vinegar have been evaluated for preservation efficacy; both have lower preservation efficiency than ethylene glycol or formalin, but their capture efficiency has rarely been assessed. Acetic acid (vinegar) is commonly used by beetle collectors as it may be an attractant for large carabids (Scheller 1984, Woodcock 2005, McCravy and Willand 2007). Although not scientifically proven, it can be assumed that vinegar 
attracts at least certain species and therefore potentially affects the captured assemblages. It has also been suggested that acetic acid (vinegar) may act as an attractant and that the low density of salt water may enhance the ability of arthropods to escape. However, the effect of this factor on capture efficiency remains unclear (Koivula et al. 2003).

Third, the number of traps and the spatial design, which account for spatial heterogeneity (Sereda et al. 2014), are key points in a sampling strategy. The use of 20 to 70 traps has been recommended for the determination of carabid species richness at a given site (Woodcock 2005). This sampling effort is often impracticable, in terms of working time both to set up and collect the traps and to identify the captured arthropods, when it has to be replicated over a network of multiple sites to account for factors such as landscape effects.

Arable fields are generally characterized by the presence of depleted arthropod communities with low diversity (Geiger et al. 2010, Postma-Blaauw et al. 2010), in which carabids and spiders have a highly heterogeneous spatial distribution (Holland et al. 1999). A large sampling effort is therefore likely to be required for accurate comparisons of the activity-density and richness values between fields managed with different cropping systems. This can be problematic in terms of feasibility. Studies investigating the functioning of these communities also require characterization of the functional composition of the arthropod community, for instance in terms of diet or body size (Rudolf 2012, Rusch et al. 2015). Such metrics describing the functional composition of arthropod communities have never been evaluated in methodological studies comparing pitfall trap designs, although it is known that pitfall traps tend to collect large arthropod individuals (Hancock and Legg 2012). Community weighted means $(\mathrm{CWM})$ of trait values are generally determined by the identity and proportion of the dominant species, with rare species making only minor contributions. A smaller sampling effort should therefore be required for the estimation of this metric than for species richness.

In this study, we aimed to test the influence of different sampling parameters on the observed differences among arthropod communities between several cropping systems. This included comparing pitfall trap characteristics, the associated preserving fluid and the sampling effort. We then used field data from three cropping systems for a simulation study in which we varied the number of pitfall traps per field. Simulation studies, which are based on artificial communities generated from preliminary data, are powerful for estimating the power and sensitivity of different sampling efforts in different scenarios (Arnold et al. 2011, Baumgardt et al. 2019). Here, we calculated the minimum sampling effort required to differentiate between the effects of contrasting cropping systems on the three metrics of carabid and spider communities that were described above.

\section{Materials and methods}

\subsection{Experimental design}

This experiment was performed at a long-term experimental site at Grignon, France (N 48.8416, E 1.9542), where cropping systems with innovative objectives and technique combinations have been implemented since 2008 (for more information, see Colnenne-David and Doré 2015, Colnenne-David et al. 2017). The experiment is located is the middle of a plateau, with a deep homogeneous loamy clay soil, within a larger cropped field and without any particular landscape element in the immediate vicinity.

We studied three cropping systems within this existing experimental design. The first was a 
productive high-environmental performance cropping system (PHEP), designed to meet high targets for both production and environmental criteria. Pesticide applications were allowed but the treatment frequency index and ploughing frequency were halved in comparison with conventional cropping systems. This system was used as a reference here, although its environmental objectives were higher than those of the conventional cropping systems used in the vicinity. The other systems were designed to meet additional environmental targets. The second cropping system was a no-pesticide cropping system (No-Pest), in which no pesticide use was tolerated, even pesticides authorized in organic agriculture. Chemical fertilizers were, however, allowed. Ploughing occurred three times over the six-year rotation of this system. The third cropping system was a low-greenhouse gas emission cropping system (L-GHG), designed to reduce greenhouse gas emissions by $50 \%$ relative to the PHEP system. These objectives were achieved through the maintenance of a continuous soil cover and the elimination of soil tillage. The targeted level of pesticide used was the same as in the PHEP system. Each cropping system was replicated on three 0.42 ha $(65 \mathrm{~m} \times 65 \mathrm{~m})$ fields, but the replicates did not always contain the same crop simultaneously (the crop rotation was the same but the crops were staggered in time, Colnenne-David et al. 2017).

\subsection{Arthropod sampling with different kinds of pitfall traps}

In 2014 and 2015, we sampled ground-dwelling arthropods (1) in a winter wheat or winter barley field for each of the three cropping systems (3 fields), and (2) in a winter oilseed rape field for the PHEP and L-GHG cropping systems (2 fields). This resulted in the sampling of five fields corresponding to five "cropping system $\times$ crop" combinations each year, with five different fields each year. The dataset thus comprises two replicates (i.e. two years) for each "cropping system $\times$ crop" combination (Fig. 1), resulting in 10 fields in total. Winter wheat and winter barley were grouped under "winter cereals" in all analyses as these crops are very close.

Arthropods were sampled with pitfall traps placed in April (15 ${ }^{\text {th }}$ April 2014 and $22^{\text {nd }}$ April 2015), May ( $6^{\text {th }}$ May 2014 and $15^{\text {th }}$ May 2015) and June ( $3^{\text {rd }}$ June 2014 and $12^{\text {th }}$ June 2015). These dates corresponded to 800,1100 and 1500 degree-days, calculated each year as the daily sum of positive mean air temperatures from January 1 onwards, in order to account for the different climatic conditions across years (Ricci et al. 2019). The pitfall traps consisted of transparent plastic containers, filled with a preserving fluid and inserted into the soil such that their rim was flush with the soil surface. They were protected from the rain by inverted opaque plastic flower-pot saucers (14 cm in diameter) supported about $2 \mathrm{~cm}$ above the soil surface with two nails (Fig. 1 A). These roofs likely did not cause any additional shade since the traps were set in a dense crop canopy that already covered the soil.

A minimal distance of $15 \mathrm{~m}$ was kept between each sampling station (location of each individual trap) to minimize interferences between traps (Digweed et al. 1995) and to avoid depopulating the fields with a too high number of traps. We combined an incomplete factorial design with two sampling designs and different trap numbers during three periods in the spring (Fig. $1 \mathrm{~B}$ ).

The sampling scheme was designed to meet our two objectives, i.e. comparing pitfall trap characteristics (size and preserving fluid) and comparing the sampling effort. In each field (one field for each crop $\times$ cropping system combination, five fields in total per year), we placed three types of pitfall traps: (1) eight large traps $(9.5 \mathrm{~cm}$ diameter, $7 \mathrm{~cm}$ high) filled with water, salt (50 $\mathrm{g} / \mathrm{l})$ and unscented detergent to break surface tension $(20 \mathrm{ml} / 1)$; (2) four small traps $(5.5 \mathrm{~cm}$ diameter, $7 \mathrm{~cm}$ high) filled with the water, salt and detergent solution; (3) four small traps $(5.5 \mathrm{~cm}$ in diameter, $7.5 \mathrm{~cm}$ high) filled with vinegar ( $8 \%$ acetic acid).

Large traps were also used for the sampling effort study. They were eight within each field in order to have a wide range of trap number per field and to analyze how this could affect the 
comparison of community metrics between cropping systems. To compare the effect of type of trap, there were only four traps per field to avoid depleting arthropod population in relatively small fields. Pitfall traps were filled to two-thirds of their volume with the preserving fluid. In April, only the eight large traps with the salt solution were placed in the field, whereas all three types of trap were placed in the field in May and June (Fig. $1 \mathrm{~B}$ ). We chose here to compare the effect of type of preserving fluid on the months where the arthropod activity-density was the highest.

The sampling stations were $12 \mathrm{~m}$ away from the edge of the fields, which were surrounded by $5 \mathrm{~m}$ wide paths with bare ground. In total, we placed each year 8 traps $\times 5$ "cropping system-crop" combinations in April and 16 traps $\times 5$ "cropping system-crop" combinations per sampling date in May and June (Fig. 1 B). Traps were left for one week and the arthropods trapped were then preserved in ethanol $(70 \%)$ for later identification.

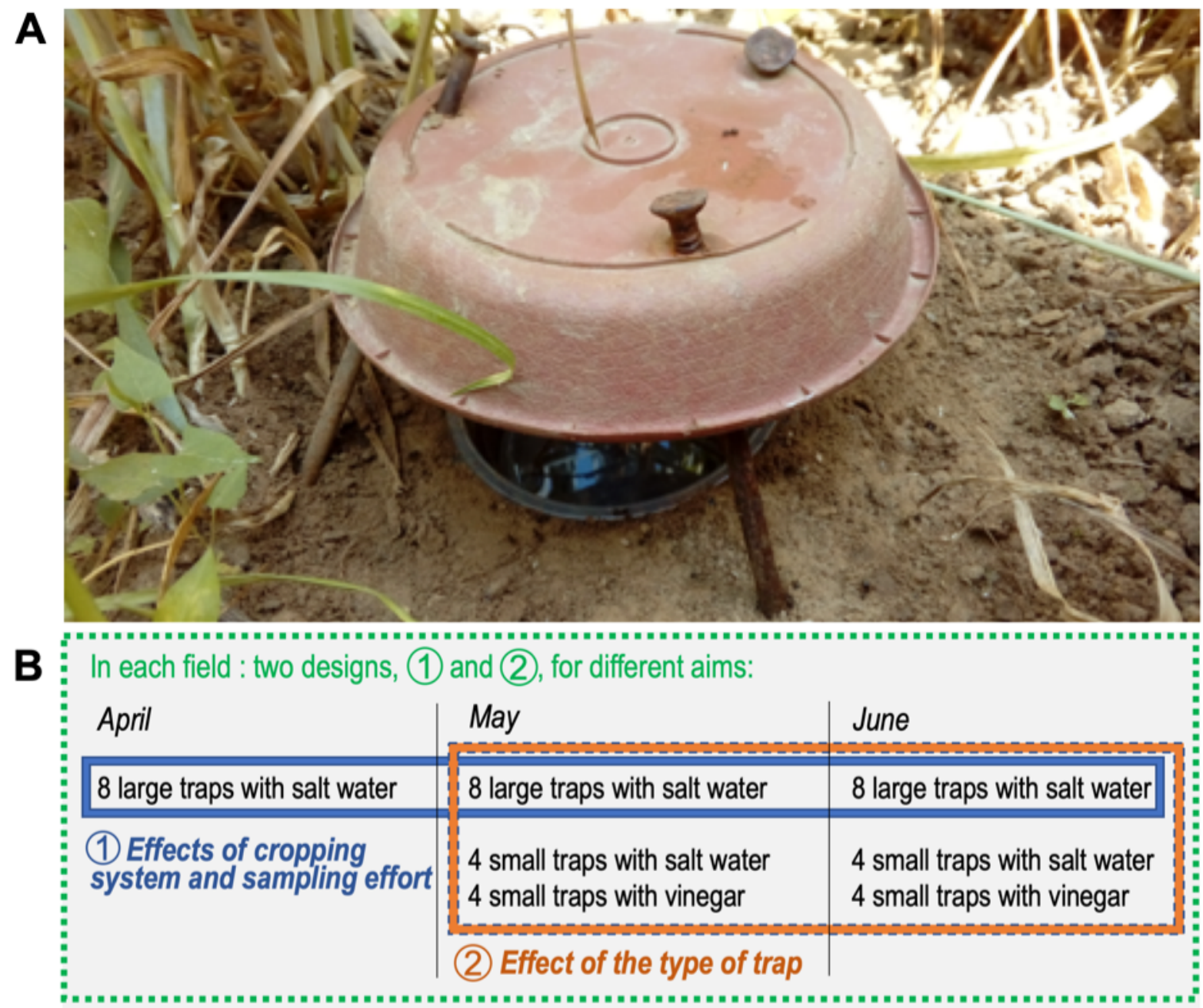

X Five fields corresponding to five cropping system - crop combinations:

- productive with high-environmental performance: wheat and oilseed rape

- no-pesticide: wheat and oilseed rape

- low-greenhouse gas emission: wheat

Two years: 2015 and 2016

Fig. 1 A: Pitfall trap in a cereal field; B: Schematic representation of the sampling design. Data were pooled over months prior to analysis. 


\subsection{Field data analyses}

Carabids were identified to species level, except for Amara spp. (Bonelli, 1810), which were determined to genus level because of identification uncertainties (Roger et al. 2012) Adult spiders were identified to genus level (Roberts 1993, 2014). Since the aim of the study was not to analyze the temporal dynamics of arthropods, we pooled, for each trap, the data from the two sampling dates (May and June) in the same year.

Statistical analyses were performed with R software, version 3.1.3 (R Development Core Team, 2015). We first analyzed the effect of trap size and type of preserving fluid on the activity-density and species (carabid) or genera (spider) richness values obtained. CWM body sizes were calculated as the mean body length weighted by the relative activity-density of each species (carabids) or genus (spiders) using the $F D$ package (Laliberté et al. 2014). Body length values where obtained from the BETSI database (Pey et al. 2014). For spiders, species data was not be used since they were identified at genus level only. Consistent with phylogenetic studies showing that spider body size is a conserved trait (Entling et al. 2010, Gonçalves-Souza et al. 2014), we assumed that there was not a wide variation in body size within spider genus and we averaged body size values for all the species available in the database at genus level before calculating CWM of spider body size. Spider body size was averaged over males and females and we did not account for the sex of trapped individuals (therefore assuming a sex ratio of 1).

We investigated the effects of trap type on the six response variables (activity-density, richness and CWM body size for carabids and spiders). We used generalized linear mixed models (lme 4 package) with a Poisson error distribution for activity-density and richness or linear mixed models (lme4 package) for CWM body size and log- or square root-transformed variables when necessary to reduce the over-dispersion (computed according to Bolker, 2020). Cropping system, crop

type and their interaction were introduced as fixed-effect factors. A random field effect was introduced to account for the variability between fields. A random station effect, nested within the field effect, was used to take into account the location of the pitfall trap within the field. The distribution of residuals was checked with the DHARMa package (Hartig 2019). The significance of the fixed effects was tested with type II analyses of deviance with Wald chi-square tests (Anova function from the car package, Fox and Weisberg 2019). In case of a significant effect, post-hoc Tukey tests were performed for multiple comparisons (multcomp package, Hothorn et al. 2008).

In order to analyse the patterns of assemblage composition according to the type of traps, a nonmetric multidimensional scaling (NMDS) ordination was performed using the Bray-Curtis similarity index (vegan package, Oksanen 2013). A three-dimensional solution was selected because it consistently maintained a low stress $(<0.2)$ across multiple runs. To identify correlations between the type of traps and NMDS axes, we tested separately the effect of trap size and of preserving fluid (on the subset of small traps) using the 'envfit' function (package vegan). This function tests for significance using a permutation test and calculate $r^{2}$ values for the correlation between trap features and the NMDs axes. To determine the association between some taxa and the type of traps, we also calculated the indicator value IndVal using the indicspecies package (Cáceres and Legendre 2009). The significance of indicator values was tested using 1000 permutation tests and Sidak's correction for multiple testing.

\subsection{Simulations}

\subsubsection{Estimation of the cropping system, crop type, field and station effects}

We investigated the sampling effort required to distinguish carabid and spider communities between contrasting cropping systems by performing a simulation study. Using the field data, we first developed statistical models relating the activity-density, richness and CWM body size of 
carabids and spiders to the kind of cropping system. As trap type affected several of these metrics, we retained only the data for large pitfall traps filled with salt solution for which we had the largest dataset (eight traps per field and per sampling date). For each trap, we pooled the data for the three sampling dates (April, May and June) in each year. Effects of cropping system, crop type and their interaction were evaluated using the same statistical approach as described in the section 2.4.1 using generalized linear mixed models or linear mixed models, including a random field effect and a random station effect.

We then used the statistical models obtained to predict three community metrics: activity-density, richness and CWM body size, for two taxonomic groups (carabids and spiders), and two crops (cereals and oilseed rape), giving 12 response variables.

\subsubsection{Simulation of a range of trap numbers crossed with a range of cropping system effects}

We first investigated the effect of the number of traps, by generating a dataset for each response variable for a number of pitfall traps ranging from 2 to 40 per field, for one or three field replicates. This sampling effort encompasses and extends beyond the most common practices in ecological and agronomic studies (e.g., Woodcock 2005, Eyre et al. 2016, Engel et al. 2017). The station effect associated with each trap and the field effect were randomly drawn from normal distributions with a variance corresponding to the random effects estimated in the descriptive statistical analyses (section 2.4.2).

Comparisons of cropping system effects were carried out for pairs of systems. The PHEP system was always used as the reference, and the positive or negative effects on arthropod communities relative to this reference were determined for each of the innovative cropping system. We simulated a range of cropping systems via their effect on activity-density, richness and CWM body size values. We varied these metrics from almost $-100 \%$ to $+150 \%$ relative to the reference cropping system. The range of positive effects was consistent with our observations and with the literature (Rusch et al. 2014, Henneron et al. 2015, Djoudi et al. 2018), while negative effects were tested for exploration purposes. We then adapted this simulation plan for analysis of the effect of the number of field replicates (see additional analyses in supporting information).

\subsubsection{Calculation of the minimum sampling effort to detect a difference between the two cropping systems}

In each tested situation (i.e., each combination of cropping system effect in a given crop, of sampling effort, for each response variable and each taxonomic group), we checked if the response variable (metrics of arthropod community) was significantly different $(P<0.05)$ between the simulated and the reference cropping system. Data for each situation were generated 1000 times to perform as many comparisons. We recorded the number of cases in which there was a significant difference between the two cropping systems with the metrics in question. Significant differences were assessed using generalized linear mixed models for the activity-density and richness variables, with a Poisson error distribution and a log-link function, and a linear mixed model for CWM body size. These models included random effects for trap location and field. This resulted in a total of 29,232,000 comparisons.

We then determined the minimum number of traps and field replicates required to obtain a significant difference between the community associated with the reference system and the community associated with the simulated cropping system in $95 \%$ of simulations. 


\section{Results}

In total, 2885 individual carabids and 9525 individual spiders were collected over the five cropcropping system combinations, two experimental years and three sampling dates per year.

\subsection{Effect of trap size and type of preserving fluid on the trapped carabid and spider communities}

Activity-density was much lower in small traps $(5.5 \mathrm{~cm}$ diameter $)$ than in large traps $(9.5 \mathrm{~cm}$ diameter, Fig. 2, Table A.1 in Supplementary materials). Average activity-densities were halved for carabids and divided by three for spiders when comparing large and small traps. In addition, activity-density for spiders was slightly lower in traps filled with vinegar than in traps filled with salt water. For salt-water traps, carabid and spider richness were higher for large than for small traps. Within small traps, richness was not affected by type of preserving fluid (Fig. 2, Table A.1). CWM body size was lower in small salt-water traps than in large salt-water traps, for both carabids and spiders. CWM body size in small vinegar-filled traps was not significantly different from that for the other two types of trap (Fig. 2, Table A.1).

The biplot derived from the NMDS tended to slightly discriminate communities sampled in large vs. small traps along the first axis (Fig. 3). The permutation test indicated that trap size was significantly related to NMDS axes, but this explained a very small fraction of the variance $\left(\mathrm{P}=1.0 \cdot 10^{-3}, \mathrm{r}^{2}=0.16\right)$. According to the IndVal calculations, large traps were associated with several spider genera, such as Oedothorax, Tenuiphantes, Erigone, Diplocephalus and Pardosa, but also several carabids, Pterostichus melanarius (Illiger, 1798) and Anchomenus dorsalis (Pontoppidan, 1763), all of them being significant indicator species of large traps.

The NMDS and permutation tests did not distinguish the traps according to the types of preserving fluid $(\mathrm{P}=0.67)$, although Notiophilus biguttatus (Fabricius, 1979) was significantly kept by IndVal as indicator of traps filled with vinegar. 

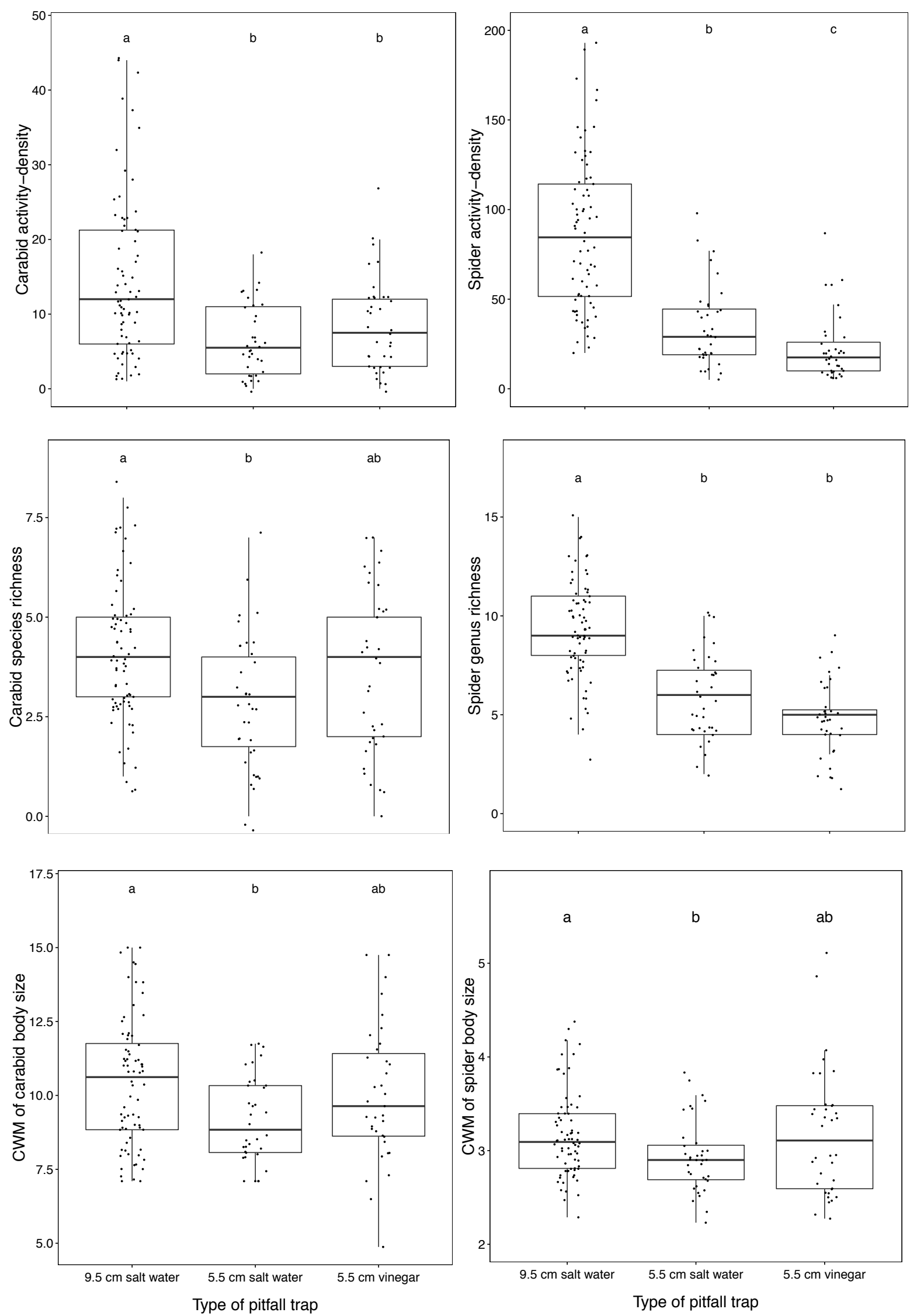

Fig. 2 Effect of the three types of pitfall trap on the activity-density, richness and CWM body size values obtained for carabids and spiders. The letters above the boxplots indicate significant differences between trap types in post-hoc Tukey tests $(P<0.05)$. 


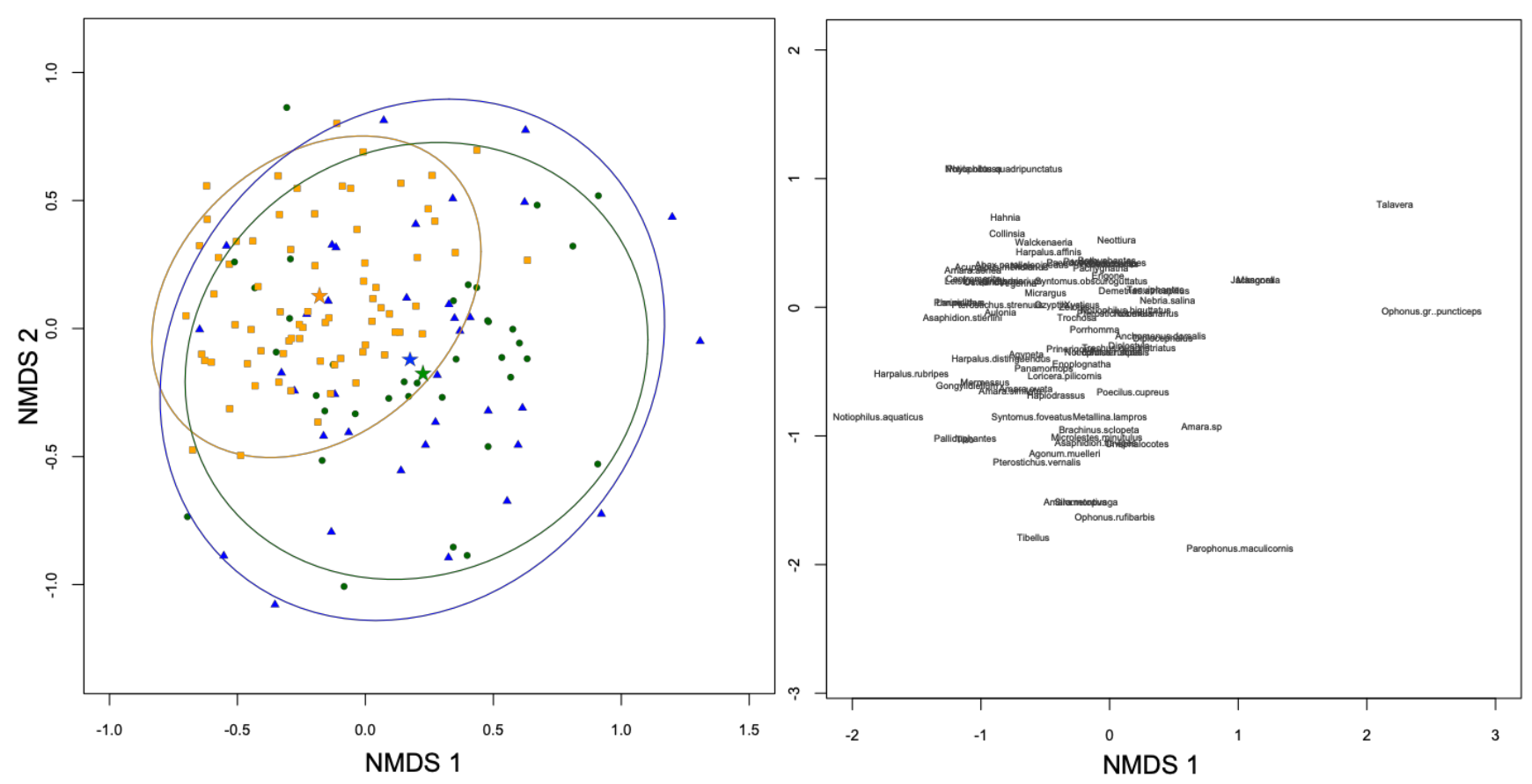

Fig. 3 Biplot representation of the NMDS ordination of the communities of carabid species and spider genera in the three types of pitfall traps (squares $=$ large traps with water; circles $=$ small traps with water; triangles $=$ small traps with vinegar). Traps (individuals, left) were described by the activity-density of the species (variables, right) they contained. Ellipses are $95 \%$ confidence intervals around the centroid position (stars).

\subsection{Differences in carabid and spiders communities between cropping systems}

The carabid and spider communities caught in the traps were generally affected by the nature of the crop or by a crop $\times$ cropping system interaction (Table 1, Fig. A.1), depending on the response variable. In addition to the effects of crop and cropping system, the statistical models summarized in Table 1 provided estimates of the random effects of field and sampling station.

Averaged over the six statistical models (Table 1), marginal coefficients of determination, accounting for fixed crop and cropping system effects, equalled $43.5 \%$. The conditional coefficients, accounting also for field and station random effects, equalled $68.2 \%$. This goodness of fit was considered acceptable in order to use the models for simulating a wider sampling effort with different values of activity-density, richness and CWM and to generate a variability comparable with that observed in the field.

\subsection{Effect of sampling effort on the ability of activity-density, richness and CWM body size estimates to distinguish between contrasting simulated communities}

The relationships between the arthropod metrics, when the differences were expressed in proportions, and the minimum sampling effort required to detect these differences were approximately the same for all three metrics (Fig. 4).

A variation of carabid or spider activity-density of less than $30 \%$ (i.e., 5 carabid or about 20 spider individuals) between a simulated and the reference PHEP system could not be detected if there were fewer than 40 traps per field (Fig. 4 and A.2). With three field replicates, five to ten traps were required to detect a variation of $50 \%$ in activity-density, corresponding to a difference of about 10 carabids or 30 to 50 individual spiders.

A minimum of three to five traps per field for carabids and five to 15 traps per field for spiders was required to differentiate between two cropping systems differing by five species or genera. 
The sampling effort increased to more than 20 traps per field for the detection of a difference in richness below two species or two genera. For CWM body size, the sampling effort required decreased sharply, from 30 to less than five traps, for a difference between two simulated cropping systems of 1 to $2 \mathrm{~mm}$ in carabids and 0.3 to $0.7 \mathrm{~mm}$ in spiders (Fig. 3).

We then represented the observed effects of the studied cropping systems on these sampling effort curves (see vertical dashed lines on Fig. 4 and A.2). In general, the observed effects of the NoPest cropping system relative to the PHEP system were so small that more than 30 or 40 traps per field, with three field replicates, would have been required to detect a significant difference for the three metrics (Fig. 3). In the L-GHG system, particularly for oilseed rape, the differences in activity-densities and in CWM body size were slightly larger and easier to detect.

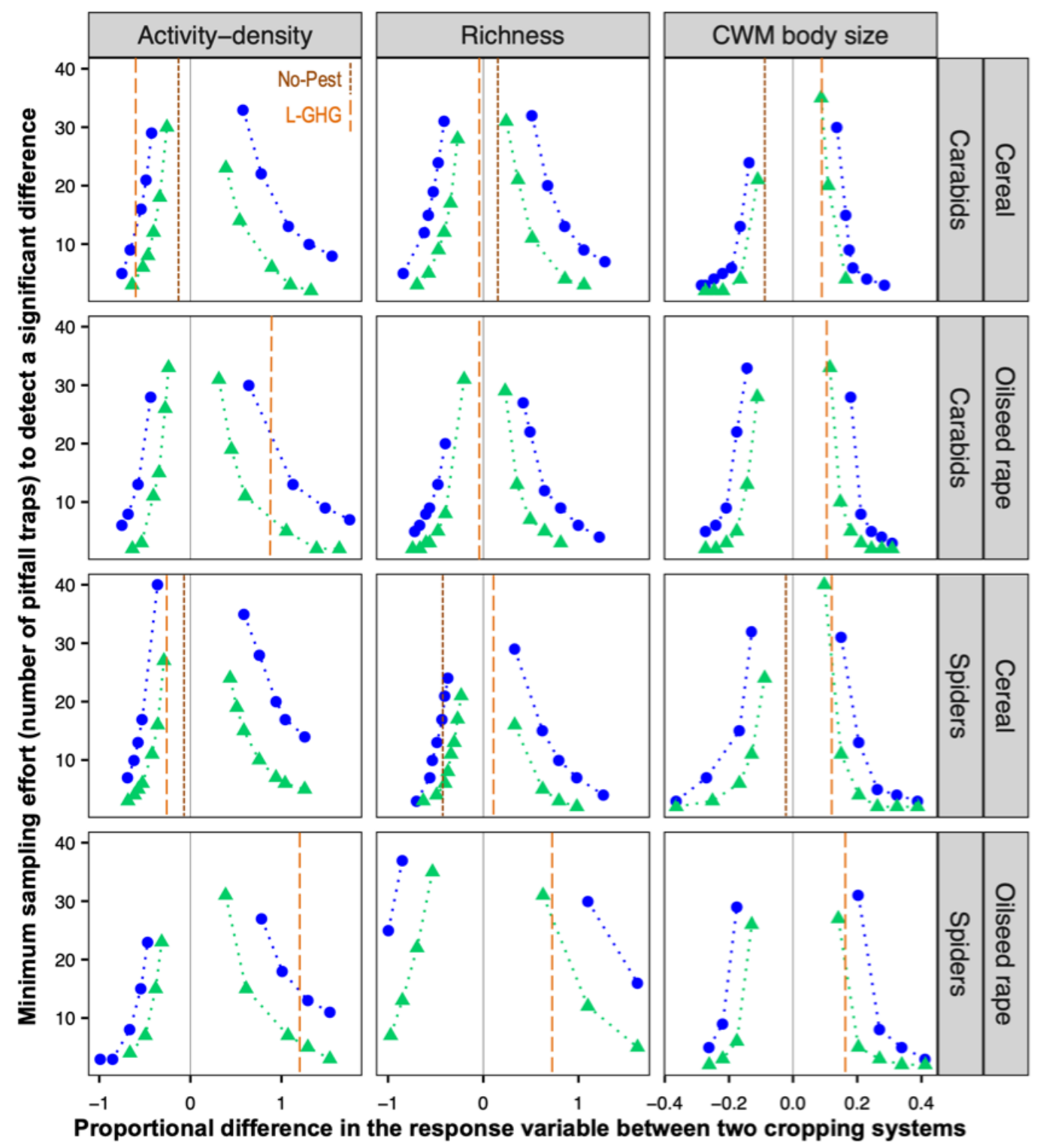

Fig. 4 Minimum sampling effort (number of traps) required to differentiate two cropping systems as a function of the simulated proportional difference in the response variables between the two systems, the productive one being taken as a reference (vertical full black line). The vertical dashed lines indicate the observed differences in the cropping system experiment (section 3.2). The response variables were carabid and spider activity-density, richness and CWM body size $(\mathrm{mm})$. Simulations were carried out with one (blue circles) or three (green triangles) field replicates. 
Table 1 Effects of the crop and cropping system on carabid and spider activity-densities, richness and CWM body size. These results were obtained with data from for large pitfall traps filled with salt water only, summed over the three sampling dates (df: degrees of freedom).

\begin{tabular}{|c|c|c|c|c|c|c|}
\hline Response variable & Explanatory variable & df & $\chi^{2}$ & P-value & Factor levels & $\begin{array}{l}\text { Fixed effects: } \\
\text { estimate } \pm \text { SE } \\
\text { Random } \\
\text { effects: SD }\end{array}$ \\
\hline Carabid activity-density & Intercept $(\mathrm{ref}=$ wheat $\mathrm{PHEP})$ & & & & & $2.81 \pm 0.27$ \\
\hline \multirow[t]{6}{*}{ (glmer, Poisson log-link function) } & Cropping system & 2 & 5.71 & 0.06 & No-Pest & $-0.19 \pm 0.38$ \\
\hline & & & & & L-GHG & $-0.09 \pm 0.39$ \\
\hline & Crop & 1 & 0.31 & 0.58 & Oilseed rape & $-1.16 \pm 0.31$ \\
\hline & Crop $\times$ cropping system & 1 & 7.89 & $4.98 \cdot 10^{-3}$ & L-GHGXoilseed rape & $-1.73 \pm 0.62$ \\
\hline & 1|Field & 1 & & & & 0.36 \\
\hline & 1IStation:Field & 1 & & & & 0.32 \\
\hline \multicolumn{7}{|c|}{$\begin{array}{l}\text { Marginal coefficient of determination }=0.47 \\
\text { Conditional coefficient of determination }=0.90\end{array}$} \\
\hline \multirow{7}{*}{$\begin{array}{l}\text { Carabid species richness } \\
\text { (lmer, square-root transformation) }\end{array}$} & \multirow{3}{*}{$\begin{array}{l}\text { Intercept }(\mathrm{ref}=\text { wheat PHEP) } \\
\text { Cropping system }\end{array}$} & & & & & $2.16 \pm 0.11$ \\
\hline & & 2 & 12.80 & $1.66 \cdot 10^{-3}$ & No-Pest & $0.05 \pm 0.13$ \\
\hline & & & & & L-GHG & $-0.40 \pm 0.13$ \\
\hline & Crop & 1 & 1.11 & 0.29 & Oilseed rape & $0.17 \pm 0.17$ \\
\hline & Crop $\times$ cropping system & 1 & 8.83 & $2.97 \cdot 10^{-3}$ & L-GHG $\times$ oilseed rape & $0.64 \pm 0.22$ \\
\hline & 1|Field & 1 & & & & 0.14 \\
\hline & 1IStation:Field & 1 & & & & 0.09 \\
\hline \multicolumn{7}{|c|}{$\begin{array}{l}\text { Marginal coefficient of determination }=0.40 \\
\text { Conditional coefficient of determination }=0.63\end{array}$} \\
\hline \multirow{7}{*}{$\begin{array}{l}\text { Carabid CWM of body size } \\
\text { (lmer) }\end{array}$} & \multirow{3}{*}{$\begin{array}{l}\text { Intercept }(\mathrm{ref}=\text { wheat } \mathrm{PHEP}) \\
\text { Cropping system }\end{array}$} & & & & & $10.73 \pm 0.88$ \\
\hline & & 2 & 1.47 & 0.48 & No-Pest & $-0.24 \pm 1.23$ \\
\hline & & & & & L-GHG & $0.82 \pm 1.23$ \\
\hline & Crop & 1 & 6.63 & $1.00 \cdot 10^{-2}$ & Oilseed rape & $-2.75 \pm 1.52$ \\
\hline & Crop $\times$ cropping system & 1 & 0.06 & 0.81 & L-GHG $\times$ oilseed rape & $0.47 \pm 1.96$ \\
\hline & 1|Field & 1 & & & & 0.63 \\
\hline & 1IStation:Field & 1 & & & & 0.33 \\
\hline \multicolumn{7}{|c|}{$\begin{array}{l}\text { Marginal coefficient of determination }=0.38 \\
\text { Conditional coefficient of determination }=0.67\end{array}$} \\
\hline Spider activity-density & Intercept (ref = wheat PHEP) & & & & & 4.86 \\
\hline \multirow{6}{*}{ (glmer, Poisson log-link function) } & Cropping system & 2 & 0.17 & 0.92 & No-Pest & $-0.09 \pm 0.25$ \\
\hline & & & & & L-GHG & $-0.09 \pm 0.25$ \\
\hline & Crop & 1 & 3.79 & $5.10 \cdot 10^{-2}$ & Oilseed rape & $-1.16 \pm 0.31$ \\
\hline & Crop $\times$ cropping system & 1 & 13.76 & $1.52 \cdot 10^{-3}$ & L-GHG $\times$ oilseed rape & $0.78 \pm 0.40$ \\
\hline & 1/Field & 1 & & & & 0.23 \\
\hline & 1IStation:Field & 1 & & & & 0.27 \\
\hline \multicolumn{7}{|c|}{$\begin{array}{l}\text { Marginal coefficient of determination }=0.28 \\
\text { Conditional coefficient of determination }=0.57\end{array}$} \\
\hline & Intercept (ref $=$ wheat PHEP) & & & & & $2.35 \pm 0.06$ \\
\hline \multirow[t]{6}{*}{ (lmer, log transformation) } & Cropping system & 2 & 6.16 & $4.59 \cdot 10^{-2}$ & No-Pest & $-0.11 \pm 0.08$ \\
\hline & & & & & L-GHG & $0.09 \pm 0.06$ \\
\hline & Crop & 1 & 27.00 & $<10^{-4}$ & Oilseed rape & $-0.52 \pm 0.10$ \\
\hline & Crop $\times$ cropping system & 1 & 13.30 & $2.65 \cdot 10^{-4}$ & L-GHG $\times$ oilseed rape & $0.47 \pm 0.13$ \\
\hline & 1|Field & 1 & & & & 0.05 \\
\hline & 1IStation:Field & 1 & & & & 0.02 \\
\hline \multicolumn{7}{|c|}{ Marginal coefficient of determination $=0.47$} \\
\hline \multicolumn{7}{|c|}{ Conditional coefficient of determination $=0.61$} \\
\hline Spider CWM of body size & Intercept (ref = wheat PHEP) & & & & & $1.15 \pm 0.04$ \\
\hline \multirow{6}{*}{ (lmer, log transformation) } & Cropping system & 2 & 14.77 & $6.19 \cdot 10^{-4}$ & No-Pest & $0.19 \pm 0.06$ \\
\hline & & & & & L-GHG & $0.25 \pm 0.02$ \\
\hline & Crop & 1 & 10.79 & $1.03 \cdot 10^{-3}$ & Oilseed rape & $-0.04 \pm 0.07$ \\
\hline & Crop $\times$ cropping system & 1 & 3.76 & $5.26 \cdot 10^{-2}$ & L-GHG $\times$ oilseed rape & $-0.19 \pm 0.09$ \\
\hline & 1|Field & 1 & & & & 0.07 \\
\hline & 1/Station:Field & 1 & & & & 0.05 \\
\hline
\end{tabular}




\section{Discussion}

We evaluated the extent to which pitfall traps were appropriate for studies characterizing the effects of arable cropping systems on the composition and structure of spider and carabid communities. We first compared the effects of pitfall trap size and type of preserving fluid on carabid and spider communities, which are the main sources of variation in pitfall trap design.

As expected, activity-density increased with trap size. Larger traps cover more ground, resulting in a higher probability to catch randomly moving individuals. Increasing the trap diameter by a factor of 1.7 (from 5.5 to $9.5 \mathrm{~cm}$ ) resulted in a similar increase in the number of carabids caught, but a tripling of the numbers of spiders caught, consistent with previous observations (Work et al. 2002, Lange et al. 2011). The effect of trap size has already been shown to differ between the species caught, as a function of their mobility (often related to their size), and the community composition results were affected by trap size. Genera from the Linyphiidae family were overrepresented in the large traps. This increase in the number of catches was proportional to trap perimeter increase for carabids (which nearly doubled, like diameter), and to trap surface increase (which was tripled in large vs small traps, $70.8 \mathrm{vs} 23.7 \mathrm{~cm}^{2}$ ) for spiders. A likely explanation is the contrasting behaviour when they encounter the rim of the trap between carabids and wandering spiders on the one hand, and Linyphiidae spiders on the other. Linyphiidae spiders can enter and explore the trap without necessarily falling into the fluid (Topping 1993).

Large traps also captured larger numbers of carabid species and spider genera. This may be because the large traps are better able to catch species with behaviours enabling them to avoid or escape from traps, as already reported for Linyphiidae spiders (Topping 1993) and carabids (Halsall and Wratten 1988). In terms of body size, CWM body size increased with trap size, for both carabids and spiders, perhaps because large species were better able to detect, avoid or escape from small traps.

For a fixed trap size, the type of preserving fluid had no effect on the variables considered, except for spider activity-density, for which vinegar-filled traps had a slightly lower trapping efficiency, suggesting a possible deterring effect. This had no significant effect on community taxonomic richness or functional composition, which was confirmed by the multivariate analysis on community composition. Despite initial expectations (McCravy and Willand 2007), there was no attractive effect of vinegar toward carabids and spiders. Overall, we can consider that traps filled with salt water or vinegar perform equally in terms of taxonomic or functional composition of the sampled communities.

These results illustrate how estimates of community composition and structure given by pitfall traps can be affected by the activity, behaviour and size of the arthropods studied (Hancock and Legg 2012). These limitations have already been reported for activity-density and richness (Topping and Sunderland 1992), but we also demonstrate here that functional characterization (here CWM body size, one of the most frequently used functional descriptors) is also affected. The use of functional indicators, such as the CWM of traits, to predict the role of arthropods in ecosystem functioning, in terms of predation for example, may therefore be risky. The correction of these sampling biases by body mass, as recommended by Engel et al. (2017), is required to obtain a reliable view of community taxonomic and functional composition and structure. Complementary sampling techniques can also be useful to increase completeness of recorded assemblages or to reduce sampling effort (Knapp et al. 2020).

When addressing cropping system comparisons, the observed differences in activity-densities and richness were not specific to our case study and are similar to those already reported in other long- 
term cropping system experiments comparing conventional, organic and conservation agriculture cropping systems (Rusch et al. 2014, Henneron et al. 2015, Djoudi et al. 2018). We then developed a simulation procedure to investigate the effect of the numbers of traps and field replicates on the ability to detect cropping system effects on carabid and spider communities, based on three metrics: activity-density, richness and CWM body size. The dataset generated took into account the important variability caused by the trap location and field effects. This simulation approach also made it possible to analyse the effect of sampling effort when comparing fields with more marked differences in community metrics than those observed.

Only very different communities could be significantly distinguished with a reasonable number of traps and field replicates. Indeed, a sampling design with ten pitfall traps per field and three field replicates was able to detect a 100\% increase in carabid or spider activity-density between two cropping systems, but not smaller increases. Five traps were sufficient to distinguish between communities differing by 20 or $30 \%$ in CWM body size (for three and one field replicates, respectively), but the required sampling effort increased sharply for differences below this threshold.

The relationships between the difference in arthropod metrics between cropping systems and the minimum sampling effort required to detect this difference were similar for activity-density and richness, contrary to the findings of Perner (2003), who reported that the required sample size for estimating richness was smaller than that for abundance parameters. A smaller number of traps was required to find differences in CWM body size between cropping systems. This finding highlights the suitability of this metric for analysing the response of arthropod communities to different management techniques. The results were also similar between the two taxa, as reported by Perner (2003). This finding suggests that these metrics and taxa are, a priori, equally suitable for use in studies aiming to detect cropping system effects. However, they displayed very different patterns of response to the three cropping systems studied here. In this case, carabid activitydensity, carabid CWM body size and spider genus richness were the variables that allowed distinguishing between cropping systems with the smallest sampling effort, whereas a much greater sampling effort was required for carabid richness. The sampling effort could be reduced by increasing the number of field replicates, but not equally for all metrics and taxa (Appendix B in Supplementary materials). This sample size reduction was the strongest for CWM body size and for all metrics in oilseed rape crops. In general, however, several metrics are sought simultaneously and sampling designs would need to be adjusted to the factor that requires the highest sampling effort. It should be kept in mind, however, that identifying spiders at genus level only did not allow us to directly compare the results on taxonomic richness for the two taxa.

\section{Conclusion}

The effects of three innovative contrasting cropping systems on arthropod communities were difficult to differentiate from other sources of variability within and between fields and years, although they were of a similar amplitude to those already reported for organic or conservation agriculture. Large trap size increased the sampling effort and increased the trapping of large species, whereas the type of preserving fluid (salt water vs. vinegar) had only a limited impact on the communities sampled. As expected, a high sampling effort was generally required for the comparison of activity-density and richness values across fields managed with different cropping systems. Also consistent with our initial expectations, a smaller sampling effort was generally required for the comparison of functional composition between two communities, than for comparisons of taxonomic richness, because this metric is less sensitive to rare taxa or to the number of individuals trapped. Finally, we found that the minimum sampling effort was much smaller for comparisons of the effects of cropping system in oilseed rape crops than in cereals. Selection of the most appropriate trap design, metrics and crops for study therefore appeared to 
be the main levers for optimizing the trade-off between sampling effort and the ability to detect arthropod community responses to habitat management.

\section{Acknowledgments}

We thank Caroline Colnenne-David and Gilles Grandeau for their collaboration for the cropping system experiment "Systèmes intégrés sous contraintes", Dominique le Floch, Thomas Bréquigny and Yoann Penel for their participation in field sampling, Jean-David Chapelin-Viscardi and Alexis Saintilan for assistance with arthropod identification and David Makowski for his valuable advice concerning statistical analyses. This work was supported by the French "Pour et sur le plan Écophyto 2018" research program.

\section{Authors' contributions}

AG and MVM conceived the ideas and designed the methodology; AG collected and analyzed the data and led the writing of the manuscript. All authors provided critical input concerning the draft versions of the manuscript and approved the final version for publication.

\section{References}

Arnold, B. F., D. R. Hogan, J. M. Colford, and A. E. Hubbard. 2011. Simulation methods to estimate design power: an overview for applied research. BMC Medical Research Methodology 11: 94.

Baumgardt, J. A., M. L. Morrison, L. A. Brennan, B. L. Pierce, and T. A. Campbell. 2019. Development of Multispecies, Long-Term Monitoring Programs for Resource Management. Rangeland Ecol. Manage. 72: 168-181.

Bolker, B. M. 2020. GLMM Frequently asked questions. Last access: 17 April 2020. https://bbolker.github.io/mixedmodels-misc/glmmFAQ.html.

Brown, G. R., and I. M. Matthews. 2016. A review of extensive variation in the design of pitfall traps and a proposal for a standard pitfall trap design for monitoring ground-active arthropod biodiversity. Ecol. Evol. 6: 3953-3964.

Cáceres, M. D., and P. Legendre. 2009. Associations between species and groups of sites: indices and statistical inference. Ecology 90: 3566-3574.

Colnenne-David, C., and T. Doré. 2015. Designing innovative productive cropping systems with quantified and ambitious environmental goals. Renew. Agric. Food Syst. 30: 487-502.

Colnenne-David, C., G. Grandeau, M. H. Jeuffroy, and T. Doré. 2017. Ambitious environmental and economic goals for the future of agriculture are unequally achieved by innovative cropping systems. Field Crop. Res. 210: 114-128.

Corti, R., S. T. Larned, and T. Datry. 2013. A comparison of pitfall-trap and quadrat methods for sampling ground-dwelling invertebrates in dry riverbeds. Hydrobiologia 717: 13-26.

Digweed, S. C., C. R. Currie, H. A. Cárcamo, and J. R. Spence. 1995. Digging out the "diggingin effect" of pitfall traps: Influences depletion and disturbance on catches of ground beetles (Coleoptera: Carabidae). Pedobiologia 39: 561-576.

Djoudi, E., A. Marie, A. Mangenot, C. Puech, S. Aviron, M. Plantegenest, and J. Pétillon. 2018. Farming system and landscape characteristics differentially affect two dominant taxa of predatory arthropods. Agr. Ecosyst. Environ. 259: 98-110.

Engel, J., L. Hertzog, J. Tiede, C. Wagg, A. Ebeling, H. Briesen, and W. W. Weisser. 2017. Pitfall trap sampling bias depends on body mass, temperature, and trap number: insights from an individual-based model. Ecosphere 8. 
Entling, W., M. H. Schmidt-Entling, S. Bacher, R. Brandl, and W. Nentwig. 2010. Body sizeclimate relationships of European spiders. J. Biogeogr. 37: 477-485.

Eyre, M. D., S. D. McMillan, and C. N. R. Critchley. 2016. Ground beetles (Coleoptera, Carabidae) as indicators of change and pattern in the agroecosystem: longer surveys improve understanding. Ecol. Indicators 68: 82-88.

Foley, J. A., N. Ramankutty, K. A. Brauman, E. S. Cassidy, J. S. Gerber, M. Johnston, N. D. Mueller, C. O’Connell, D. K. Ray, P. C. West, C. Balzer, E. M. Bennett, S. R. Carpenter, J. Hill, C. Monfreda, S. Polasky, J. Rockström, J. Sheehan, S. Siebert, D. Tilman, and D. P. M. Zaks. 2011. Solutions for a cultivated planet. Nature 478: 337.

Fox, J., and S. Weisberg. 2019. An R companion to applied regression. Third edition. Sage, Thousand Oaks CA, https://socialsciences.mcmaster.ca/jfox/Books/Companion/.

Geiger, F., J. Bengtsson, F. Berendse, W. W. Weisser, M. Emmerson, M. B. Morales, P. Ceryngier, J. Liira, T. Tscharntke, C. Winqvist, S. Eggers, R. Bommarco, T. Part, V. Bretagnolle, M. Plantegenest, L. W. Clement, C. Dennis, C. Palmer, J. J. Onate, I. Guerrero, V. Hawro, T. Aavik, C. Thies, A. Flohre, S. Hanke, C. Fischer, P. W. Goedhart, and P. Inchausti. 2010. Persistent negative effects of pesticides on biodiversity and biological control potential on European farmland. Basic Appl. Ecol. 11: 97-105.

Gonçalves-Souza, T., J. A. F. Diniz, and G. Q. Romero. 2014. Disentangling the phylogenetic and ecological components of spider phenotypic variation. Plos One 9.

González, E., M. Seidl, T. Kadlec, M. Ferrante, and M. Knapp. 2020. Distribution of ecosystem services within oilseed rape fields: effects of field defects on pest and weed seed predation rates. Agr. Ecosyst. Environ. 295: 9.

Halsall, N. B., and S. Wratten. 1988. The efficiency of pitfall trapping for polyphagous predatory Carabidae. Ecol. Entomol. 13: 293-299.

Hancock, M. H., and C. J. Legg. 2012. Pitfall trapping bias and arthropod body mass. Insect Conserv. Divers. 5: 312-318.

Hartig, F. 2019. DHARMa: residual diagnostics for hierarchical (multi-Level / mixed) regression models. R package version 0.2.4. http://florianhartig.github.io/DHARMa/.

Henneron, L., L. Bernard, M. Hedde, C. Pelosi, C. Villenave, C. Chenu, M. Bertrand, C. Girardin, and É. Blanchart. 2015. Fourteen years of evidence for positive effects of conservation agriculture and organic farming on soil life. Agron. Sustain. Dev. 35: 169-181.

Holland, J. M., and S. Smith. 1999. Sampling epigeal arthropods: an evaluation of fenced pitfall traps using mark-release-recapture and comparisons to unfenced pitfall traps in arable crops. Entomol. Exp. Appl. 91: 347-357.

Holland, J. M., J. N. Perry, and L. Winder. 1999. The within-field spatial and temporal distribution of arthropods in winter wheat. Bull. Entomol. Res. 89: 499-513.

Hothorn, T., F. Bretz, and P. Westfall. 2008. Simultaneous inference in general parametric models. Biometrical Journal 50: 346-363.

Jonsson, M., R. Kaartinen, and C. S. Straub. 2017. Relationships between natural enemy diversity and biological control. Curr. Opin. Insect Sci. 20: 1-6.

Jud, P., and M. H. Schmidt-Entling. 2008. Fluid type, dilution, and bitter agent influence spider preservation in pitfall traps. Entomol. Exp. Appl. 129: 356-359.

Knapp, M., and J. Ruzicka. 2012. The effect of pitfall trap construction and preservative on catch size, species richness and species composition of ground beetles (Coleoptera: Carabidae). Eur. J. Entomol. 109: 419-426.

Knapp, M., E. Baranovská, and P. Jakubec. 2016. Effects of bait presence and type of preservative fluid on ground and carrion beetle samples collected by pitfall trapping. Environ. Entomol. 45: 1022-1028.

Knapp, M., J. Knappová, P. Jakubec, P. Vonička, and P. Moravec. 2020. Incomplete species lists produced by pitfall trapping: How many carabid species and which functional traits are missing? Biol. Conserv. 245: 108545. 
Koivula, M., D. J. Kotze, L. Hiisivuori, and H. Rita. 2003. Pitfall trap efficiency: do trap size, collecting fluid and vegetation structure matter? Entomol. Fenn. 14: 1-14.

Kromp, B. 1999. Carabid beetles in sustainable agriculture: a review on pest control efficacy, cultivation impacts and enhancement. Agr. Ecosyst. Environ. 74: 187-228.

Laliberté, E., P. Legendre, and B. Shipley. 2014. FD: measuring functional diversity from multiple traits, and other tools for functional ecology. R package version 1.0-12.

Lange, M., M. M. Gossner, and W. W. Weisser. 2011. Effect of pitfall trap type and diameter on vertebrate by-catches and ground beetle (Coleoptera: Carabidae) and spider (Araneae) sampling. Methods in Ecology and Evolution 2: 185-190.

Lövei, G. L., and T. Magura. 2011. Can carabidologists spot a pitfall? The non-equivalence of two components of sampling effort in pitfall-trapped ground beetles (Carabidae). Community Ecology 12: 18-22.

Marc, P., A. Canard, and F. Ysnel. 1999. Spiders (Araneae) useful for pest limitation and bioindication. Agr. Ecosyst. Environ. 74: 229-273.

McCravy, K., and J. Willand. 2007. Effects of pitfall trap preservative on collections of carabid beetles (Coleoptera: Carabidae). The grat lakes entomologist 40: 154-165.

Ng, K., P. S. Barton, W. Blanchard, M. J. Evans, D. B. Lindenmayer, S. Macfadyen, S. McIntyre, and D. A. Driscoll. 2018. Disentangling the effects of farmland use, habitat edges, and vegetation structure on ground beetle morphological traits. Oecologia 188: 645-657.

Oksanen, J. 2013. Multivariate analysis of ecological communities in R: vegan tutorial. R package version 1.7 .

Perner, J. 2003. Sample size and quality of indication - a case study using ground-dwelling arthropods as indicators in agricultural ecosystems. Agr. Ecosyst. Environ. 98: 125-132.

Pey, B., M.-A. Laporte, J. Nahmani, A. Auclerc, Y. Capowiez, G. Caro, D. Cluzeau, J. Cortet, T. Decaëns, F. Dubs, S. Joimel, M. Guernion, C. Briard, F. Grumiaux, B. Laporte, A. Pasquet, C. Pelosi, C. Pernin, J.-F. Ponge, S. Salmon, L. Santorufo, and M. Hedde. 2014. A thesaurus for soil Invertebrate trait-based approaches. PLOS ONE 9: e108985.

Postma-Blaauw, M. B., R. G. M. d. Goede, J. Bloem, J. H. Faber, and L. Brussaard. 2010. Soil biota community structure and abundance under agricultural intensification and extensification. Ecology 91: 460-473.

Ricci, B., C. Lavigne, A. Alignier, S. Aviron, L. Biju-Duval, J. C. Bouvier, J. P. Choisis, P. Franck, A. Joannon, S. Ladet, F. Mezerette, M. Plantegenest, G. Savary, C. Thomas, A. Vialatte, and S. Petit. 2019. Local pesticide use intensity conditions landscape effects on biological pest control. Proceedings of the Royal Society B-Biological Sciences 286.

Roberts, M. J. 1993. The Spiders of Great Britain and Ireland, Harley Books; Compact edition. $714 \mathrm{p}$.

Roberts, M. J. 2014. Araignées de France et d'Europe, Delachaux et Niestlé. 384 p.

Roger, J.-L., O. Jambon, and G. Bouger. 2012. Clé de détermination des carabidés des paysages agricoles du nord-ouest de la France. https://osur.univ-rennes1.fr/za-armorique/news/clede-determination-des-carabidae-des-paysages-agricoles-du-nord-ouest-de-la-france.html.

Rudolf, V. H. W. 2012. Seasonal shifts in predator body size diversity and trophic interactions in size-structured predator-prey systems. J. Anim. Ecol. 81: 524-532.

Rusch, A., K. Birkhofer, R. Bommarco, H. G. Smith, and B. Ekbom. 2014. Management intensity at field and landscape levels affects the structure of generalist predator communities. Oecologia 175: 971-983.

Rusch, A., K. Birkhofer, R. Bommarco, H. G. Smith, and B. Ekbom. 2015. Predator body sizes and habitat preferences predict predation rates in an agroecosystem. Basic Appl. Ecol. 16: 250-259.

Scheller, H. V. 1984. Pitfall trapping as the basis for studying ground beetle (Carabidae) predation in spring barley. Tidsskrift for Planteavl 88: 317-324. 
Schmidt, M. H., Y. Clough, W. Schulz, A. Westphalen, and T. Tscharntke. 2006. Capture efficiency and preservation attributes of different fluids in pitfall traps. J. Arachnol. 34: 159-162.

Sereda, E., T. Blick, W. Dorow, V. Wolters, and K. Birkhofer. 2014. Assessing spider diversity on the forest floor: Expert knowledge beats systematic design. J. Arachnol. 42: 44-51.

Thérond, O., M. Duru, J. Roger-Estrade, and G. Richard. 2017. A new analytical framework of farming system and agriculture model diversities. A review. Agron. Sustain. Dev. 37: 21.

Topping, C. J. 1993. Behavioural responses of three linyphiid spiders to pitfall traps. Entomol. Exp. Appl. 68: 287-293.

Topping, C. J., and K. D. Sunderland. 1992. Limitations to the use of pitfall traps in ecologicalstudies exemplified by a study of species in a field of winter-wheat. J. Appl. Ecol. 29: 485491.

Woodcock, B. A. 2005. Pitfall trapping in ecological studies, pp. 37-57. In S. R. Leather (ed.), Insect sampling in forest ecosystems.

Work, T. T., C. M. Buddle, L. M. Korinus, and J. R. Spence. 2002. Pitfall trap size and capture of three taxa of litter-dwelling arthropods: Implications for biodiversity studies. Environ. Entomol. 31: 438-448. 